\title{
BMJ Open Sequence analysis to assess labour market participation following vocational rehabilitation: an observational study among patients sick-listed with low back pain from a randomised clinical trial in Denmark
}

Louise Lindholdt, ${ }^{1,2}$ Merete Labriola, ${ }^{1,2}$ Claus Vinther Nielsen, ${ }^{1,2}$ Trine Allerslev Horsbøl, ${ }^{3}$ Thomas Lund ${ }^{1,2,4}$

To cite: Lindholdt L, Labriola M, Nielsen CV, et al. Sequence analysis to assess labour market participation following vocational rehabilitation: an observational study among patients sicklisted with low back pain from a randomised clinical trial in Denmark. BMJ Open 2017;7:e015661. doi:10.1136/ bmjopen-2016-015661

- Prepublication history for this paper is available online. To view these files please visit the journal online (http://dx.doi org/10.1136/bmjopen-2016015661).

Received 20 December 2016 Revised 6 June 2017 Accepted 8 June 2017

\section{CrossMark}

${ }^{1}$ Section of Clinical Social Medicine and Rehabilitation, Department of Public Health, Aarhus University, Aarhus, Denmark

${ }^{2}$ DEFACTUM, Central Denmark Region, Aarhus, Denmark

${ }^{3}$ The Danish Cancer Society, Copenhagen, Denmark

${ }^{4}$ Department of Occupational Medicine, Danish Ramazzini Centre, University Research Clinic, Regional Hospital West Jutland, Herning, Denmark

Correspondence to Dr Louise Lindholdt; LOLISO@ rm.dk

\section{ABSTRACT}

Introduction The return-to-work (RTW) process after long-term sickness absence is often complex and long and implies multiple shifts between different labour market states for the absentee. Standard methods for examining RTW research typically rely on the analysis of one outcome measure at a time, which will not capture the many possible states and transitions the absentee can go through. The purpose of this study was to explore the potential added value of sequence analysis in supplement to standard regression analysis of a multidisciplinary RTW intervention among patients with low back pain (LBP). Methods The study population consisted of 160 patients randomly allocated to either a hospital-based brief or a multidisciplinary intervention. Data on labour market participation following intervention were obtained from a national register and analysed in two ways: as a binary outcome expressed as active or passive relief at a 1-year follow-up and as four different categories for labour market participation. Logistic regression and sequence analysis were performed.

Results The logistic regression analysis showed no difference in labour market participation for patients in the two groups after 1 year. Applying sequence analysis showed differences in subsequent labour market participation after 2 years after baseline in favour of the brief intervention group versus the multidisciplinary intervention group.

Conclusion The study indicated that sequence analysis could provide added analytical value as a supplement to traditional regression analysis in prospective studies of RTW among patients with LBP.

\section{INTRODUCTION}

Considerable amounts of research have been conducted to evaluate the effectiveness of interventions to prevent work disability due to low back pain (LBP) with varying effect. ${ }^{1-4}$ Knowledge about prognostic factors for work resumption after rehabilitation is still
Strengths and limitations of this study

- The use of registries of social benefits linked to each patient ensured zero loss to follow-up and a low risk of misclassification bias.

- The Danish Register for Evaluation of Marginalisation used for this study is particularly applicable in longitudinal analyses.

- Sequence analysis is a novel approach for assessing longitudinal employment data that are capable of capturing the dynamics in the labour market participation process

- The study population was relatively small, and a larger study population may presumably have had an impact on the results.

- Sequence analysis is considered an exploratory method rather than a method for hypothesis testing, which means that sequence analysis cannot be adjusted for covariates and confounders and cannot answer the question of causality.

limited, ${ }^{5}$ and there is no consensus regarding when and how work resumption should be measured, and furthermore little is known about work sustainability outcomes after rehabilitation interventions. ${ }^{6-8}$

While the term return to work (RTW) is commonly used as an outcome measure following an intervention among sickness absent patients due to LBP, the extent to which it has a shared and agreed upon meaning is limited, ${ }^{9}$ and there is no gold standard for how it should be measured. The measurement of RTW following temporary work disability is often conducted as a cross-section, measured as a dichotomous outcome at a definite point in time ensuing a specific event, often onset of disability or time of a specific intervention. 
However, as the employees RTW status can change and be measured throughout a labour market participation process, for example, by recurrences of sickness absence or gradual recovery from an injury or illness, RTW may be seen as a time-to-event outcome, ${ }^{910}$ which enables the analysis of the individual RTW process. ${ }^{11-13}$

Besides the most commonly used dichotomising of the outcome into 'returned yes/no' at a certain follow-up point, and with this yielding no information of when or for how long the person returned, some studies use non-evidence-based thresholds as for example 1 week in some cases ${ }^{14-16}$ and 4 weeks in others. ${ }^{17}$ This latter approach must be considered an improvement, but whether or not it reflects long-term re-employment and work participation is unknown. A method study comparing different measures of RTW concluded that choice of RTW outcome should depend on study purpose; simple cross-sectional methods are sufficient in prediction of RTW and analysis of risk factors, whereas methods capturing relapses are recommended when sustainability, prognosis and vulnerability are in focus. ${ }^{18}$

Standard methods typically contain the analysis of one outcome at a time, and analyses based on such measures do not cover the many possible states and transitions sickness absent patients go through. Previously, studies have used multistate models in an attempt to investigate these multiple states among sickness absent patients due to LBP, where the intention was to investigate whether patients changed between the states, the probability of being in either of the states at any given time and the duration within the states. ${ }^{19} 20$

In order to capture both the complexity and handle the long-term multiple outcome by comparing, sorting and grouping, sequence analysis has been introduced as a method to investigate labour market participation and explore characteristics and transitions. ${ }^{21} 22$ A sequence analysis can be seen as an instrument that intends to explain the effects and events at a micro level, such as labour market entry and RTW, on the basis of macrolevel causes. $^{21}$

The purpose of this study was to explore potential added analytical value of sequence analysis as supplement to standard regression analysis when assessing the effect of two LBP interventions on labour market participation.

\section{METHODS}

\section{Design and study population}

From June 2006 to April 2010, 192 patients were referred to the Spine Center, Diagnostic Center, Regional Hospital Silkeborg, Denmark, to participate in a randomised controlled trial comparing a brief and a multidisciplinary RTW intervention. To be included in the study, patients should be sickness absent either $\geq 4$ weeks from unemployment or $\geq 12$ weeks from employment with non-specific LBP as their primary reason for sickness absence. This led to a final study population of 160 patients after excluding 32 patients from the original population who did not fulfil the inclusion criteria. Additional exclusion criteria were low back surgery within the past year and severe mental health disorder, which were criteria that had already been taken into account in the population of 192 patients. Of the 160 patients, 83 were randomised to the brief intervention and 77 to the multidisciplinary intervention. At the first visit, all patients completed a comprehensive baseline questionnaire, regarding health, disability, social aspects and individual factors. The content of the questionnaire is described in detail elsewhere. ${ }^{1}$ After completing the questionnaire, the patients underwent a clinical examinationbyand received advice from a rheumatologist and a physiotherapist,a process similar for all patients. ${ }^{12}$ Subsequently the patients were randomised. Afterwards, the patients randomised to the multidisciplinary intervention were scheduled for an interview with a case manager. The case manager's function was to make an inquiring interview with the patient based on the existing health assessment devised by the rheumatologist and the physiotherapist. In interaction, the case manager and the patient had to devise a tailored rehabilitation plan, establish realistic goals for the entire process of handling pain and the possible uncertainty regarding labour market participation and RTW. The patients were in contact with the case manager for at least once depending on need and progress. ${ }^{12}$ Table 1 provides a sample description of the study population.

\section{Data}

Baseline data for this study were collected using comprehensive questionnaires filled out by the patients. Follow-up information on work status and social transfer payments were obtained from the Danish Register for Evaluation of Marginalisation (DREAM), which contains weekly information on all social transfer payments to all Danish citizens since mid-1991. ${ }^{23}$ The weekly information indicates whether a person has received for instance sickness benefits, unemployment benefits, early retirement pension, etc, where benefits received for 1 day will appear as 1 week based on a hierarchy. ${ }^{24}$

\section{Outcomes}

Data on labour market participation and employment were measured in two ways: as a binary cross-sectional outcome expressed as active or passive relief for the logistic regression analysis, based on their specific types of social transfer payments in week 52 after baseline. The active category indicated an active course where the patients already were employed or a course that pointed in the direction of work inclusion. The passive category indicated that the patients were still on sickness absence or received other social benefits, implying that they were not ready to participate in working life.

Based on the logistic regression outcome, the outcome for the sequence analysis was extended to include four different categories of labour market participation and RTW during a 2-year follow-up period: (1) sickness absence, (2) employment, (3) active relief or (4) passive 
Table 1 Baseline characteristics of the study population

Sociodemographic variables

Women (\%)

Age, mean (years) (SD)

Married or cohabiting partner (\%)

Children (\%)

Completed vocational education (\%)

Medication

Weekly use of non-prescription medication

Weekly use of strong analgesic medication

Low-back pain (the LBP Rating Scale)

\section{Level of low back pain at baseline, mean (SD)*}

Average level of low back pain, mean (SD)

The level of physical pain within the last 4 weeks

None (\%)
Very light (\%)
Light (\%)

Medium (\%)

Severe (\%)

Very severe (\%)

Previous sick leave due to LBP

$\begin{array}{ll}\text { Never (\%) } & 21(25.9) \\ \text { 1-2 times (\%) } & 12(14.8) \\ \text { 3-4 times (\%) } & 15(18.5) \\ >4 \text { times (\%) } & 33(40.7)\end{array}$

Duration of sick leave due to LBP within the last 3 years

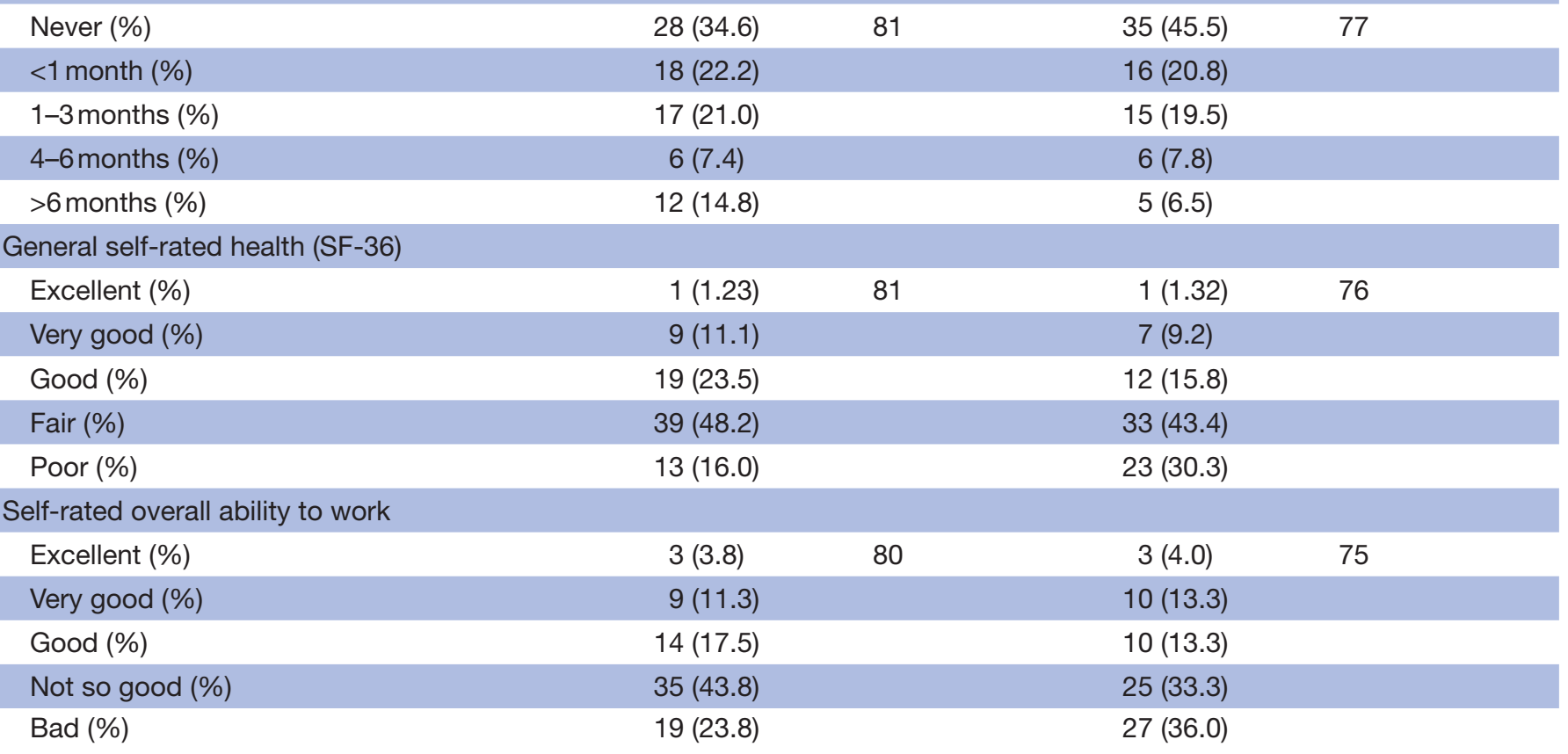

Continued
Brief intervention

$\mathrm{n}(\%)$ or mean

(SD)

\section{Multidisciplinary \\ intervention}

n (\%) or mean

(SD)

\section{$\mathbf{N}$}

$\begin{array}{rrrr}36(43.4) & 83 & 40(52.0) & 77 \\ 40.1(11.2) & 83 & 39.5(10.0) & 77 \\ 62(76.5) & 81 & 62(80.5) & 77 \\ 56(68.3) & 82 & 55(71.4) & 77 \\ 56(68.3) & 82 & 49(63.6) & 77\end{array}$

$\begin{array}{llll}70(85.4) & 82 & 64(86.5) & 74 \\ 11(14.9) & 74 & 22(31.0) & 71\end{array}$

$\begin{array}{llll}5.3(2.2) & 81 & 5.8(2.4) & 77 \\ 6.2(2.0) & 81 & 6.4(2.3) & 77\end{array}$

$\begin{array}{llll}0(0.0) & 80 & 0(0.0) & 72\end{array}$

$2(2.5) \quad 0(0.0)$

5 (6.3)

$7(9.7)$

$28(35.0) \quad 21(29.2)$

$34(42.5) \quad 29(40.3)$

$11(13.8)$

$21(25.9)$

81

$23(29.9)$

77

$17(22.1)$

$11(14.3)$

$26(33.8)$

$\begin{array}{ll}5(18.5) & 11(14.3) \\ 3(40.7) & 26(33.8)\end{array}$

$18(22.2)$

$17(21.0)$

$6(7.4)$

$27(36.0)$ 


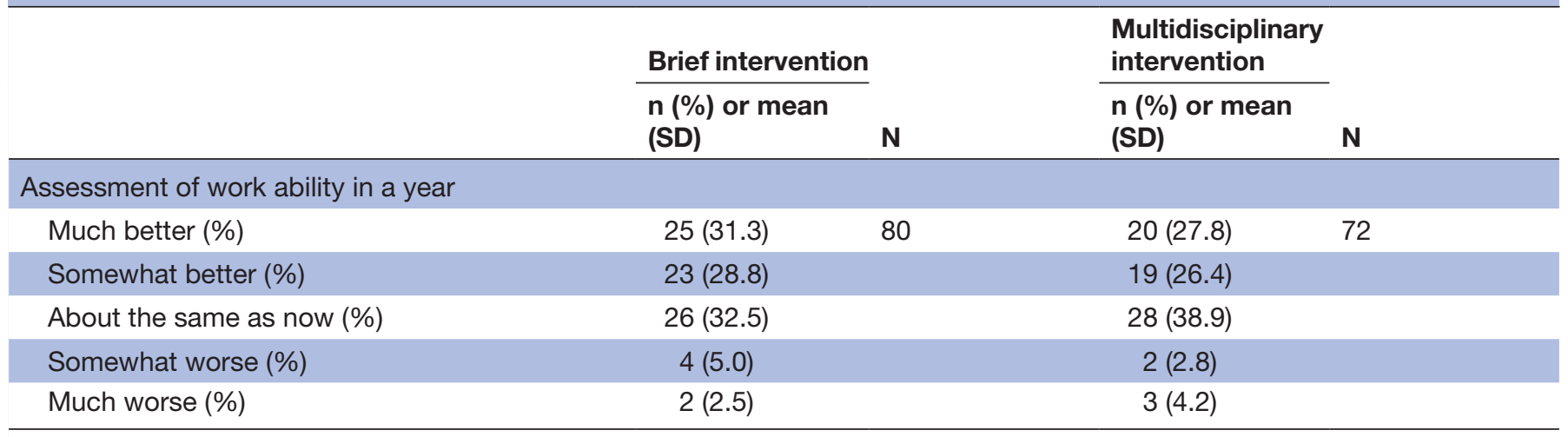

*Scale from 1 to 10.

LBP, low back pain; SF-36, 36-Item Short Form Health Survey.

relief. The sickness absence category contained only the benefits related to temporary sickness absence (part time and full time), not including benefits related to permanent work disability. Employment was defined as the time gaps with no social transfer payments, where the patients were classified as self-supporting and consequently as working. ${ }^{25}$ Active relief was defined as benefits which pointed towards labour market inclusion, for example, vocational rehabilitation benefit, retraining or flexible job. Passive relief was defined as for example social assistance, disability pension or retirement pension, which all indicated that the patients were not ready to participate in working life or had made a complete withdrawal from the labour market.

\section{Statistical methods}

An initial bivariate analysis of differences in baseline characteristics between the two intervention groups was performed using a t-test or a $\mathrm{X}^{2}$ test, depending on type of variable.

Logistic regression methods were first used to investigate the association between the two intervention groups focusing on labour market participation at 1-year of follow-up. The logistic regression modelled the probability of active or passive relief in week 52, where the association was expressed by ORs with $95 \%$ CIs.

Sequence analysis was used to analyse successions of labour market states. A sequence is defined as an ordered string of elements and episodes expressed on a time axis, where elements are specific states and episodes are defined as successive identical elements. ${ }^{26} 27$ These elements are tied to either fixed points in time or to fixed positions. ${ }^{28}$ In this study, sequences will show a complete event history of labour market participation during a 2-year follow-up period. This means that an individual sequence is the succession of the observed labour market statuses in each week from baseline to 2-year follow-up. Sequence analysis is an exploratory method rather than a method for hypothesis testing and cannot be adjusted for confounders and covariates. This extended follow-up time was chosen in an attempt to comprise as much information as possible about the patients' labour market trajectories.Inspired by Brzinsky-Fay, ${ }^{22}$ a volatility indicator and an integration indicator were calculated based on the data from the sequence analysis. The volatility indicator expresses the proportion of episodes within employment and active relief in relation to total episodes. ${ }^{22}$ In the present study, both employment and active relief reflected positive statuses, which indicated that frequent changes between these outcomes entailed a high quality of transitions. The integration indicator reflects how quickly and to what extent the patient entered employment. ${ }^{22}$ It was assessed as the sum of number of sequence positions in employment, which were weighted by their position within the sequence. ${ }^{22}$ This indicated that the longer or more episodes in employment, the higher the quality of the labour market participation process. Both indicators ranged from 0 to 1 , with higher order values representing more favourable sequences. The results will be presented as mean values despite the fact that data were not normal distributed, since data estimates would be incomprehensible if they were reported as median values (table 2 ).

By applying a sequence index plot it was made possible to visualise each patient's history of events from baseline to 2-year follow-up, where the dimensions of sequence data, consisting of observations, time points and outcome categories, were plotted in a graph for each randomisation group (figure 1). ${ }^{29}$ Each point in this graph showed one of the four outcome categories (indicated by a respective colour) of a particular patient at a particular week. ${ }^{29}$ In addition, there was made a status proportion plot, which displayed the relative proportion of each outcome category representing the patients' status for every week (figure 2) ${ }^{29}$ Contrary to the sequence index plot, there was no information in this graph concerning individual sequences.

The software package STATA V.12.1 was used for all the statistical analyses. The study was performed according to the STROBE (Strengthening The Reporting of Observational Studies in Epidemiology) guidelines. 
Table 2 Aggregated characteristics of labour market entry sequences

\begin{tabular}{|c|c|c|c|c|}
\hline & \multicolumn{2}{|c|}{ Brief intervention } & \multicolumn{2}{|c|}{ Multidisciplinary intervention } \\
\hline & Mean (SD) & $\begin{array}{l}\text { Minimum/ } \\
\text { maximum }\end{array}$ & Mean (SD) & $\begin{array}{l}\text { Minimum/ } \\
\text { maximum }\end{array}$ \\
\hline Sickness absence & $44.28(32.66)$ & $1 / 105$ & $48.74(29.11)$ & $1 / 105$ \\
\hline Employment & $30.20(30.47)$ & $0 / 102$ & $21.50(32.31)$ & $0 / 104$ \\
\hline \multicolumn{5}{|l|}{ Average number of episodes in } \\
\hline Sickness absence & $1.75(1.17)$ & $1 / 7$ & $1.57(1.23)$ & $1 / 8$ \\
\hline Employment & $2.23(2.28)$ & $0 / 8$ & $1.20(1.78)$ & $0 / 9$ \\
\hline Active relief & $2.16(2.39)$ & $0 / 9$ & $1.26(1.41)$ & $0 / 6$ \\
\hline Integration indicator & $0.33(0.33)$ & 0/0.98 & $0.24(0.35)$ & $0 / 0.98$ \\
\hline Volatility indicator & $0.54(0.29)$ & $0 / 0.94$ & $0.46(0.25)$ & $0 / 0.89$ \\
\hline
\end{tabular}

\section{Ethics}

The study was discussed with the regional research ethics committee (Central Denmark Region for Research Ethics Committees, Viborg, Denmark). Approval was not considered necessary by the committee, because all participants received the best available clinical care, and no biological material was involved. All procedures followed were in accordance with the ethical standards of the responsible committee on human experimentation (institutional and national) and with the Helsinki
Declaration of 1975 , as revised in 2000. All patients signed informed consent, and the study was approved by the Danish Data Protection Agency (no 1-16-02-9509).

\section{RESULTS}

The initial bivariate analysis indicated statistically insignificant differences in the baseline characteristics between patients in the randomisation groups.
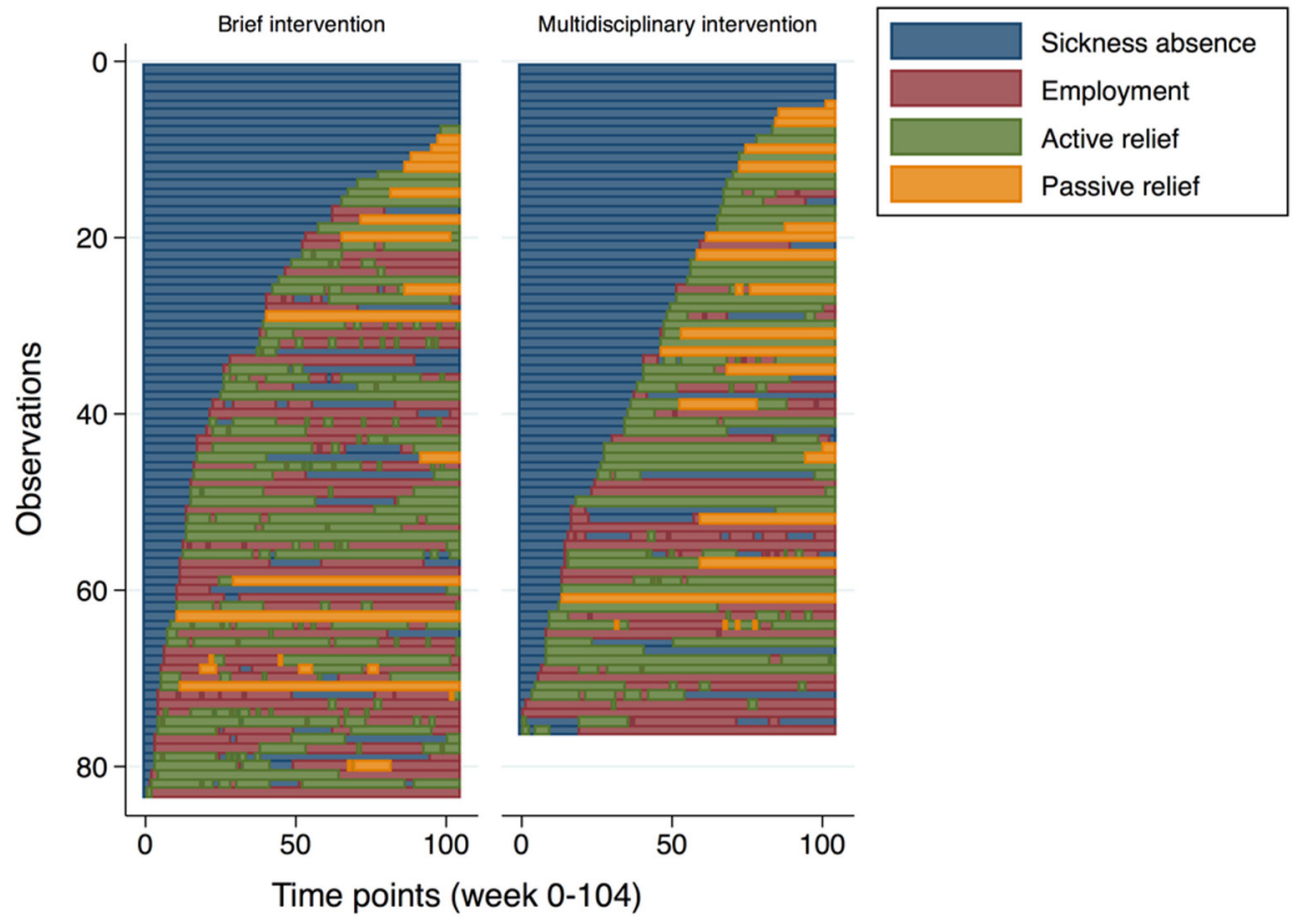

Figure 1 Sequence index plot visualising the history of events in an individual level from baseline to 2-year follow-up for each randomisation group $(n=160)$. 

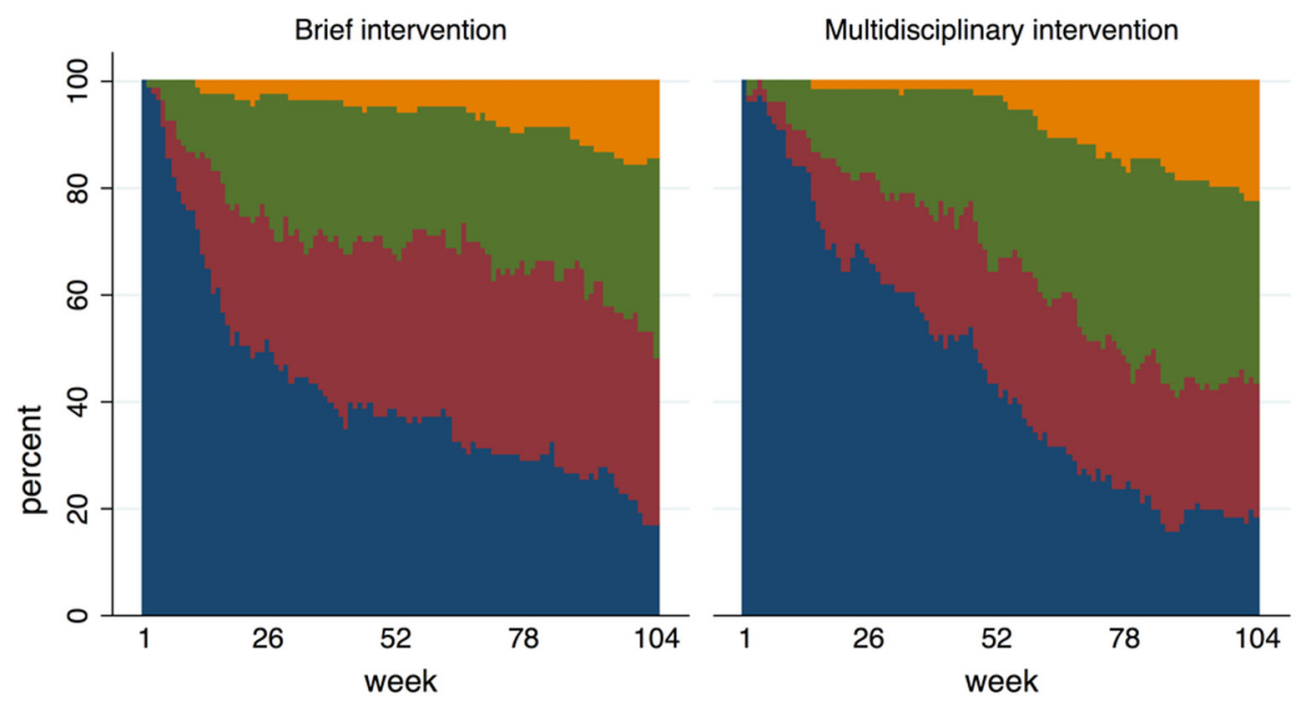

Multidisciplinary intervention

Passive relief

Active relief

Employment

Sickness absence

Figure 2 Status proportion plot visualising the relative proportion of each outcome category for each randomisation group $(n=160)$.

The logistic regression analysis at the 52-week follow-up showed no difference in labour market participation for patients in the randomisation groups $(\mathrm{OR}=1.03,95 \% \mathrm{CI}$ 0.55 to 1.93$)$. Further adjustment for age, gender, marital status, educational level, general self-rated health and previous episodes of sickness absence due to LBP did not alter this result. This lack of statistical significance was further supported when running a t-test.

Through sequence analysis, trajectories of labour market participation were examined and sequence patterns between the randomisation groups were investigated. During the 2-years of follow-up, the sequence analysis indicated some variation in all outcomes between the randomisation groups (table 2; figures 1 and 2). Patients receiving the multidisciplinary intervention had longerspells of and spent more time on sickness absence benefits, had shorter employment episodes and less time spent in employment than those receiving the brief intervention.

In terms of active and passive relief, the average duration in active relief was 24.2 weeks for patients in the brief intervention and 26.7 weeks for those in the multidisciplinary intervention. The average duration in passive relief was 6.4 weeks for patients in the brief intervention and 8 weeks for those in the multidisciplinary intervention.

The results further showed an average number of episodes of 6.4 in total for the patients in the brief intervention, and 4.3 for those in the multidisciplinary intervention, which indicates how many transitions the patients had between the four outcome categories. For patients in the brief intervention, the minimum number of episodes was 1 and the maximum number was 20 .
For patients in the multidisciplinary intervention, the minimum number of episodes was 1 and the maximum number was 23. Within the different outcome categories, the patients in the brief intervention had more episodes compared with those in the multidisciplinary intervention during the 2-years of follow-up, except for those within passive relief.

The volatility indicator was 0.54 in the brief intervention and 0.46 in the multidisciplinary intervention, indicating that the sequences in the brief intervention had a higher quality of transitions. The integration indicator for the patients in the brief intervention was 0.33 and 0.24 for the patients in the multidisciplinary intervention, suggesting a better integration into working life for those who participated in the brief intervention.

\section{DISCUSSION}

Using sequence analysis and register data on employment and social benefits made it possible to visualise the consecutive process of labour market participation and RTW in detail. The results showed that during the 2-years of follow-up, the labour market sequences in the brief intervention had a higher quality of transitions compared with those in the multidisciplinary intervention. The patients randomised to the brief intervention had fewer weeks with sickness absence and more weeks in employment, which implies that the patients in the brief intervention were better integrated in the labour market than the patients in the multidisciplinary intervention. These results indicated that the sequence analysis provided additional analytical value and insight in supplement to the standard regression analysis. 
Furthermore, the results showed that within a 2-year follow-up period the average number of episodes was 6.39 for patients in the brief intervention and 4.33 for patients in the multidisciplinary intervention. This does not imply that the multidisciplinary intervention is better due to the lower amount of episodes. The total number of episodes in both groups rather indicate that RTW might be a long and resource consuming process, ${ }^{9}{ }^{10}$ where the sickness absent patients, irrespective of randomisation group, may change between multiple states; a result also indicated in previous studies. ${ }^{19} 20$

As stated in Oyeflatenetal, ${ }^{19}$ there is a need for a follow-up period of several years to obtain a sufficient overview of the RTW outcome. Since all patients are long-term sickness absent at baseline, the time dimension consisting of 2-year follow-up was selected in preparation of capturing as much information as possible and getting an adequate picture of the labour market participation process. Contrary, it is important that the follow-up period is not too long compared with the time of the intervention,since it thus might be debatable whether the effect can be attributed to the intervention or other external factors. The aim of supplementing the regression analysis with sequence analysis was to explore the potential information in the 'black box' between baseline and the follow-up at 52 weeks, as well as the period after the logistic regression follow-up. In this context, 1 year of follow-up has been deemed to be too close to baseline, since the patients at baseline were far from the labour market, and it is a well-known fact that the RTW process after long-term sickness absence might be long. This is supported by looking at the status proportion plot (figure 2) where it appears that after 52 weeks there is still a considerable percentage of patients who receive sickness benefits, whereas a 2-year period appears to give a more accurate picture of the patients' labour market participation.

Strength of this particular study is the use of register data. The existence of registries of social benefits linked to each patient ensures zero loss to follow-up and a low risk of misclassification bias. ${ }^{23}$ A main strength of using the DREAM Register in relation to RTW is the ability to establish measures that capture the dynamics of the labour market participation process. ${ }^{18}$ The DREAM Register is particularly applicable in longitudinal analyses, where the focus is on the possible transitions between different social benefits or the duration of receiving the benefits. Because DREAM data seem to have a high validity and is highly applicable for the present study design, DREAM data were chosen to form the basis for the division of outcome measures. The four outcome measures were chosen in an attempt to increase the understanding of the patients' labour market participation and RTW process. The division has been made on the basis of the regulations and instructions in relation to the policy areas of sickness absence and employment in a Danish context. Concurrently, this division is based on a subjective judgement of how the data are optimally fitted to the design of the study. Whether this division of the outcome measures should be made differently in other studies depends on the context.

One of the limitations of the current study is the small study population. The study population was further reduced from 192 to 160 patients, since 32 patients were not registered as receiving sickness benefits in the DREAM Register at baseline, and it was not possible to identify their labour market participation at baseline accurately. A larger study population may presumably have had an impact on the results, but since the purpose of this study was to assess the effect of a multidisciplinary intervention on RTW and primarily to use outcome measures capturing relapses and cumulated labour market participation using sequence analysis, it does not seem to be a major limitation.

The results of this study can only be compared with previous studies of RTW with regard to the overall findings due to differences in design, method and outcome measures. As sequence analysis is a relatively new method for assessing longitudinal data in relation to the RTW process, it is difficult to compare directly with similar studies: to our knowledge, only one other study has used this analytical approach in this context, reaching similar conclusions regarding additional analytical information derived from the same data as used in a traditional regression analysis. ${ }^{30}$ Other previous studies have used multistate models in an attempt to investigate multiple states among sickness absent patients due to LBP. ${ }^{19} 20$ By using multistate models, the core statistical measure comprises the intensities for shifting between different states and computes the probability of being in a specific state, ${ }^{20}{ }^{2531}$ whereas sequence analysis is capable of exploring transitions and states through sequence patterns, and examining trajectories of labour market participation at a micro level.

A limitation of sequence analysis is that it does not provide measures of robustness in the form of p-values to investigate statistical significant differences between the randomisation groups. Sequence analysis is considered an exploratory method rather than a method for hypothesis testing, which means that sequence analysis cannot be adjusted for covariates and confounders and cannot answer the question of causality. ${ }^{21}{ }^{26}$ Due to this, sequence analysis is best used in combination with other methods and cannot replace methods like event history models. ${ }^{2126}$

In this study, sequence analysis provided added value to the assessment of the RTW process by describing the process over time, instead of merely analysing time to events or effects at a given point in time. The results are a typology of episodes and transition types that, besides providing a useful insight and overview, could be used as a well-grounded argument for investigating certain trajectories of interest in the aim of studying labour market participation following long-term sickness absence. ${ }^{21}$ 


\section{CONCLUSION}

The study showed no differences in labour market participation for patients in two different intervention groups when analysed with logistic regression analysis using outcomes based on point estimates. Applying sequence analysis showed differences in subsequent labour market participation between the two intervention groups. The study indicates that sequence analysis can provide added analytical value as a supplement to traditional regression analysis in prospective studies of RTW among patients with LBP.

Acknowledgements The authors thank Ole Kudsk Jensen and the staff from the Spine Center, Diagnostic Center, Regional Hospital Silkeborg, Denmark, for their effort to include and treat the patients in this study.

Contributors LL, ML and TL conceived and designed the study. CVN designed the intervention. LL and TL analysed the data. LL, ML and TL wrote the manuscript. CVN and TAH contributed to the first manuscript draft with important intellectual content. $\mathrm{LL}, \mathrm{ML}$ and TL revised accordingly and wrote the final manuscript. LL, ML, TL, CVN and TAH approved the final version.

Funding The study is part of the PUSAM project funded by the Danish Working Environment Research Fund (Project no 24-2013-09).

Competing interests None declared.

Ethics approval The Danish Data Protection Agency approved the study (no 200741-1278).

Provenance and peer review Not commissioned; externally peer reviewed.

Data sharing statement Information on how to obtain additional data is available by emailing the corresponding author at loliso@rm.dk.

Open Access This is an Open Access article distributed in accordance with the Creative Commons Attribution Non Commercial (CC BY-NC 4.0) license, which permits others to distribute, remix, adapt, build upon this work non-commercially, and license their derivative works on different terms, provided the original work is properly cited and the use is non-commercial. See: http://creativecommons.org/ licenses/by-nc/4.0/

(c) Article author(s) (or their employer(s) unless otherwise stated in the text of the article) 2017. All rights reserved. No commercial use is permitted unless otherwise expressly granted.

\section{REFERENCES}

1. Jensen $\mathrm{C}$, Jensen $\mathrm{OK}$, Christiansen $\mathrm{DH}$, et al. One-year follow-up in employees sick-listed because of low back pain: randomized clinical trial comparing multidisciplinary and brief intervention. Spine 2011;36:1180-9.

2. Jensen C, Jensen OK, Nielsen CV. Sustainability of return to work in sick-listed employees with low-back pain. Two-year follow-up in a randomized clinical trial comparing multidisciplinary and brief intervention. BMC Musculoskelet Disord 2012;13:156.

3. Bendix AF, Bendix T, Labriola M, et al. Functional restoration for chronic low back pain. Two-year follow-up of two randomized clinical trials. Spine 1998;23:717-25.

4. Palmer KT, Harris EC, Linaker C, et al. Effectiveness of communityand workplace-based interventions to manage musculoskeletalrelated sickness absence and job loss: a systematic review. Rheumatology 2012;51:230-42.

5. Burstrom B, Nylen L, Clayton S, et al. How equitable is vocational rehabilitation in Sweden? A review of evidence on the implementation of a national policy framework. Disabil Rehabil 2011;33:453-66.

6. Ahlgren A, Bergroth A, Ekholm J, et al. Work resumption after vocational rehabilitation: a follow-up two years after completed rehabilitation. Work 2007;28:343-54.
7. Alexanderson KA, Borg KE, Hensing GK. Sickness absence with lowback, shoulder, or neck diagnoses: an 11-year follow-up regarding gender differences in sickness absence and disability pension. Work 2005;25:115-24.

8. Hensing G, Alexanderson K, Allebeck P, et al. How to measure sickness absence? Literature review and suggestion of five basic measures. Scand J Public Health 1998;26:133-44.

9. Young AE, Roessler RT, Wasiak R, et al. A developmental conceptualization of return to work. J Occup Rehabil 2005;15:557-68.

10. Wasiak R, Young AE, Roessler RT, et al. Measuring return to work. J Occup Rehabil 2007;17:766-81.

11. Krause N, Lund T. Return to work after occupational injury. In: Barling J, Frone MR, The psychology of workplace safety. Washington, DC: American Psychological Association, 2004:265.

12. Bültmann U, Franche RL, Hogg-Johnson S, et al. Health status, work limitations, and return-to-work trajectories in injured workers with musculoskeletal disorders. Qual Life Res 2007;16:1167-78.

13. Butler RJ, Johnson WG, Baldwin ML. Managing work disability: why first return to work is not a measure of success. ILR Review 1995;48:452-69.

14. Nielsen MB, Bültmann U, Madsen IE, et al. Health, work, and personal-related predictors of time to return to work among employees with mental health problems. Disabil Rehabil 2012;34:1311-6.

15. Labriola M, Lund T, Christensen KB, et al. Multilevel analysis of individual and contextual factors as predictors of return to work. $J$ Occup Environ Med 2006;48:1181-8.

16. Lund T, Labriola M, Christensen KB, et al. Return to work among sickness-absent Danish employees: prospective results from the Danish Work Environment Cohort Study/National Register on Social Transfer Payments. Int J Rehabil Res 2006;29:229-35.

17. Biering K, Nielsen TT, Rasmussen K, et al. Return to work after percutaneous coronary intervention: the predictive value of self-reported health compared to clinical measures. PLoS One 2012;7:e49268.

18. Biering $\mathrm{K}, \mathrm{Hj}$ øllund $\mathrm{NH}$, Lund $\mathrm{T}$. Methods in measuring return to work: a comparison of measures of return to work following treatment of coronary heart disease. J Occup Rehabil 2013;23:400-5.

19. Oyeflaten I, Lie SA, Ihlebæk CM, et al. Multiple transitions in sick leave, disability benefits, and return to work. A 4-year follow-up of patients participating in a work-related rehabilitation program. BMC Public Health 2012;12:748.

20. Lie SA, Eriksen HR, Ursin H, et al. A multi-state model for sick-leave data applied to a randomized control trial study of low back pain. Scand J Public Health 2008;36:279-83.

21. Brzinsky-Fay C. The measurement of school-to-work transitions as processes.Eur Soc 2014;16:213-32.

22. Brzinsky-Fay C. Lost in transition? Labour market entry sequences of school leavers in Europe. Eur Sociol Rev 2007;23:409-22.

23. Hjollund $\mathrm{NH}$, Larsen FB, Andersen JH. Register-based follow-up of social benefits and other transfer payments: accuracy and degree of completeness in a Danish interdepartmental administrative database compared with a population-based survey. Scand J Public Health 2007;35:497-502.

24. Arbejdsmarkedsstyrelsen. DREAM version 32 manual. Copenhagen: Arbejdsmarkedsstyrelsen, 2014.

25. Pedersen J, Bjorner JB, Burr H, et al. Transitions between sickness absence, work, unemployment, and disability in Denmark 20042008. Scand J Work Environ Health 2012;38:516-26.

26. Abbott A. Sequence analysis: new methods for old ideas. Annu Rev Sociol 1995;21:93-113.

27. Brzinsky-Fay C, Kohler U, Luniak M. Sequence analysis with Stata. Stata J 2006;6:435-60.

28. Brzinsky-Fay $\mathrm{C}$, Kohler U. New developments in sequence analysis. Sociol Methods Res 2010;38:359-64.

29. Brzinsky-Fay C. Graphical representation of transitions and sequences. In: Blanchard P, Bühlmann F, Gauthier JA, eds. Advances in sequence analysis: theory, method applications, life course research and social policies 2. New York, Heidelberg, Dordrecht, London: Springer, 2014:pp.265-284.

30. Pedersen P, Lund T, Lindholdt L, et al. Labour market trajectories following sickness absence due to self-reported all cause morbidity-a longitudinal study. BMC Public Health 2016;16:337.

31. Andersen PK, Keiding N. Multi-state models for event history analysis. Stat Methods Med Res 2002;11:91-115. 